This item was submitted to Loughborough's Research Repository by the author.

Items in Figshare are protected by copyright, with all rights reserved, unless otherwise indicated.

\title{
Studies on Information as an Asset III: Views of Information Professionals
}

PLEASE CITE THE PUBLISHED VERSION

PUBLISHER

Institute of Information Scientists

LICENCE

CC BY-NC-ND 4.0

\section{REPOSITORY RECORD}

Oppenheim, Charles, Joan Stenson, and Richard M.S. Wilson. 2019. "Studies on Information as an Asset III: Views of Information Professionals”. figshare. https://hdl.handle.net/2134/295. 


\section{Loughborough $\checkmark$ University}

This article has been submitted to Loughborough University's Institutional Repository by the author.

\section{Views of information professionals on information as an asset}

Charles Oppenheim*, Department of Information Science, Loughborough University, Loughborough, LE11 3TU. E-mail: c.oppenheim@lboro.ac.uk

Joan Stenson, Department of Information Science, Loughborough University, Loughborough, LE11 3TU. E-mail: j.a.stenson@lboro.ac.uk

Richard M.S. Wilson, The Business School, Loughborough University, Loughborough, LE11 3TU. E-mail: r.m.wilson@lboro.ac.uk

*To whom correspondence should be addressed. 


\begin{abstract}
This paper reports findings from a small number of interviews (six) with internationally-active information professionals and academics using a semistructured interview instrument. The value of information, its identification, use and impact are discussed. Seven themes were explored within the broad context of the role of information assets in enhancing organisational effectiveness. These themes were: value of information and its measurement; impact of the concepts of knowledge management and intellectual capital; acquisition and use of information and the embedding of good practice; relevance of these questions to other industry sectors; identification of attributes of information assets; information assets and organisational effectiveness; and the impact of identification and measurement of information assets on the perceptions of senior managers. The major conclusion was that studies in this field should take a very broad view of information assets and should not be restricted to valuation in financial terms.
\end{abstract}

\title{
Introduction
}

Six open-ended interviews with internationally-active information professionals and academics were conducted during 2001 as part of the research project "The attributes of information as an asset, its measurement and role in enhancing organisational effectiveness”. These interviews were conducted at the $4^{\text {th }}$ Northumbria Conference on Performance Measurement in Library and Information Services held in Pittsburgh, Pennsylvania, USA, 12-14 August 2001.

The interviewees comprised: a Senior Academic from a well-established New Zealand university; the Research Director of a well-established USA university with many years experience of research work in the library and information field; the Head of a UK based Research School in the library and information science field; the Director of Information Services of a large UK based specialist library; the University Librarian of a well-known USA university; and the Executive Director of Information Services of a well-established Australian university. The interviewees were selected for a number of reasons. The Senior Academic, Research Director and the Head of the UK based Research 
School are very well known in the information science field. They have all worked extensively in the performance measurement field where the value of information is a key if neglected issue. The Director of Information Services of the large UK based specialist library and the University Librarian were selected because they were seen to have a stake in this research. The benefits which library and information services bring to organisations are often long-term (Abell, 1994) and librarians face a constant challenge to communicate the value of their libraries and ultimately of themselves. Finally, the Executive Director of Information Services was selected because of his interest in activity-based costing for libraries and information services on which he consulted worldwide.

Activity-based costing is defined as:

“Activity-based costing identifies activities performed in an organisation and determines their cost and performance” (Brimson, 1991, p.11).

Activity-based costing differs from traditional cost accounting where costs are accumulated and controlled in total by cost category for each organisational unit; under activity-based costing costs are associated with what the organisation does (Brimson, 1991, p.16). Activity-based costing when applied to library and information services encourages a focus on the short-term rather than long-term value creation. Whilst revealing the costs of information activities in some detail, it does little to help senior managers identify the value-generating elements in their organisations. It was thought that the Executive Director of Information Services would have strong views on a value-oriented approach.

The six interviewees can all be seen as having differing perspectives due to their academic, research and practical management experience in libraries and information services. It should, however, be noted, that these interviews are not intended to be representative Rather the views of individuals who have many years' experience in the information field were of interest in exploring issues which impacted on a wide variety of stakeholders including academics, researchers, students, business managers, consultants, information professionals, 
librarians and policymakers. The six interviews were also seen as a good opportunity to test the appropriateness of a change of direction, which the research had undergone. This change of direction involved the focusing of the research on the long-term future economic benefits of information assets rather than on their measurement or valuation. Information assets are defined as:

\section{Information assets comprise resources that are or should be documented and which promise future economic benefit.}

This change of direction was based on earlier interviews conducted by the research team with senior executives and information managers (Oppenheim, Stenson and Wilson, 2002) who argued that trying to value information assets was "going down a blind alley". Rather, the ways in which information added value to organisations was the area where both senior executives and information managers focused their attention. The Advisory Committee of the research project, made up of accounting professionals, business managers, academics and information professionals, agreed that a change of approach from valuation to value creation was appropriate.

\section{Method}

All six interviewees were contacted by email prior to the conference and asked to participate in interviews. All six agreed. The interviews were conducted informally in the conference hotel lobby and meeting rooms. The interviewees were supplied with the interview schedule in advance and so had an opportunity to familiarise themselves with the issues to be addressed. Several of the interviewees also attended a conference presentation given by the interviewer (J.S.) where the background, methodology and early results of the larger research project were reported. The interviews were tape-recorded and later transcribed and analysed using a constant comparison method based in grounded theory (Glaser and Strauss, 1967). The interviews were between twenty minutes and half an hour in length and were all conducted between 12 and 16 August 2001. 
An open-ended interview schedule (see Appendix I) was used to conduct these interviews. An open-ended interview schedule was seen as appropriate as these interviewees had many years' experience in their field and were expected to have strong opinions, which could be best captured in a less structured interview format. The seven themes included in the schedule were mainly background questions on ideological or practical approaches to information assets and their impact on organisational effectiveness. Also included, however, were more specific questions, which asked interviewees to identify attributes of a given set of information assets. These information assets had been identified and revised in earlier work (Oppenheim, Stenson and Wilson, 2001). Their applicability to a wider user group than already investigated was of interest.

The seven themes addressed in the interviews were:

Theme 1 . The value of information and its measurement.

Theme 2. The impact of the concepts of knowledge management and intellectual capital.

Theme 3. The acquisition and use of information and the embedding of good practice.

Theme 4. The relevance of these questions to other industry sectors. Are they more relevant issues for some sectors?

Theme 5. Identification of attributes of information assets.

Theme 6. Information assets and organisational effectiveness.

Theme 7. Impact of identification and measurement of information assets on the perceptions of senior managers.

(For a full copy of the interview schedule please see Appendix I).

Theme 1. The value of information and its measurement.

None of the six interviewees said they could see any real progress being made in the value of information field. Indeed, measuring the value of information was full of difficulties. One major difficulty was the "shareability" of information. Information is shareable; it can be given away and retained at the same time 
(Yates-Mercer and Bawden, 2002, p.20). This was seen by the Senior Academic interviewed as the greatest barrier to investment in information:

"Managers do not want to invest in something they cannot own or see”.

A second reason given by Executive Director of Information Services was a lack of understanding among people of information as a concept in itself. Without a basic grasp of the fundamental concept of information as an abstract yet valuecreating entity it was very difficult to convince people that effort should be expended in valuing it:

“Trying to value information is asking the wrong question - we need to develop into people a better understanding”.

One of the clearest and most strongly felt reasons for no progress being made in measuring the value of information was the situational nature of information use. The dynamic nature of information and its ability to change value in particular situations and contexts or for particular individuals was seen as being critical. Measuring information independently was not a viable option; there was a need to:

“Measure information within particular contexts”(Research Director).

These comments confirmed to us that our change of direction from valuing information assets to looking at the long-term future economic benefits which information assets promise was valid.

Theme 2. The impact of concepts of knowledge management and intellectual capital.

The concepts of knowledge management and intellectual capital have been both connected with and divorced from information management in its traditional form. The concepts of knowledge management and intellectual capital are not 
new by any means. Peter Drucker (1969) in his important work “The age of discontinuity" described the "knowledge economy" in terms of a shift not only in terms of numbers of people or "knowledge workers" employed but also in terms of the importance and value of what it produced:

"Where the farmer was the backbone of any economy a century or two ago - not only in numbers of people employed, but in importance and value of what he produced - knowledge is now the main cost, the main investment, and the main product of the advanced economy and the livelihood of the largest group in the population” (Drucker, 1969, p. 323).

By the 1990’s Tom Peters (Peters, 1992, p.123) argued that all organisations were "knowledge-based societies". Peters saw a growing focus on knowledge as the key to the future of the organisation:

“The ability to rope in knowledge, learn from what other parts of the organisation are doing, and reinvent the organisation in a flash, becomes arguably, the principle source of future value added” (Peters, 1992, p. 123).

Knowledge management is defined by Skyrme (1998, p. 534) as:

"the explicit and systematic management of vital knowledge and its associated processes of creating, gathering, organising, diffusion, use and exploitation”.

Intellectual capital is defined by Edvinsson and Malone (1997, p.368) as: 
"the possession of knowledge, applied experience, organisational technology, customer relationships, and professional skills that provides a competitive edge in the market.”

Finally, information management is defined by Best (1996, p. 4) as:

"the effective production, storage, retrieval and dissemination of information in any format and on any medium to support business objectives".

Table 1 Comparison of concepts

\begin{tabular}{|c|c|c|c|c|c|}
\hline $\begin{array}{l}\text { Knowledge } \\
\text { management }\end{array}$ & $\begin{array}{l}\text { Proposed } \\
\text { Impact }\end{array}$ & $\begin{array}{l}\text { Intellectual } \\
\text { capital }\end{array}$ & $\begin{array}{l}\text { Proposed } \\
\text { impact }\end{array}$ & $\begin{array}{l}\text { Information } \\
\text { management }\end{array}$ & $\begin{array}{l}\text { Proposed } \\
\text { impact }\end{array}$ \\
\hline $\begin{array}{l}\text { Organisational } \\
\text { learning } \\
\text { Reinvention } \\
\text { (Peters, 1992). }\end{array}$ & $\begin{array}{l}\text { Future value } \\
\text { added }\end{array}$ & $\begin{array}{l}\text { Recognition of } \\
\text { experience, } \\
\text { knowledge and } \\
\text { skills (Edvinsson } \\
\text { and Malone, } \\
\text { 1997). }\end{array}$ & $\begin{array}{l}\text { Competitive } \\
\text { edge }\end{array}$ & $\begin{array}{l}\text { Life cycle } \\
\text { approach } \\
\text { (Best, 1996). }\end{array}$ & $\begin{array}{l}\text { Support } \\
\text { business } \\
\text { objectives }\end{array}$ \\
\hline $\begin{array}{l}\text { Systematic } \\
\text { management } \\
\text { Life cycle } \\
\text { approach } \\
\text { (Skyrme, } \\
\text { 1998). }\end{array}$ & $\begin{array}{l}\text { Improved } \\
\text { exploitation }\end{array}$ & $\begin{array}{l}\text { Organisational } \\
\text { technology and } \\
\text { customer } \\
\text { relationships } \\
\text { (Edvinsson and } \\
\text { Malone, 1997). }\end{array}$ & $\begin{array}{l}\text { Competitive } \\
\text { edge }\end{array}$ & & \\
\hline
\end{tabular}

Both knowledge management and information management take a systematic life cycle approach where a process of creation, use, distribution and ultimately disposal or reuse is foremost. However, knowledge management goes further than information management in linking such processes to organisational learning and the creation of future value added. Information management aims to support business objectives, whatever they may be. Intellectual capital 
has a dual role in enhancing structural agility through technology and customer relationship management and providing a focus on internal skills and competencies. The proposed outcome for organisations that adopt the intellectual capital approach is improved competitive edge.

Yet, knowledge management and intellectual capital, it is argued, have done little to improve the effectiveness of organisations. Enhanced organisational effectiveness encompasses all of the proposed outcomes shown in Table 1. Knowledge management and intellectual capital are simply management terms, which mistake tacit knowledge as Polyani (1958) described it for explicit or transferable knowledge. This knowledge when expressed becomes information (Wilson, 2002, p. 25-28). For our interviewees, an information management approach was preferable; the ability of knowledge management and intellectual capital concepts to be applied diverse contexts was seen as a drawback rather than a benefit:

“The concepts do not help information professionals at all. There are so many different contexts and it is not practiced” (Research Director).

The Executive Director of Information Services saw a lack of practical examples of the concepts being applied as the major reason why they had little impact:

“There has been lots of theorising and developing of models but it has never really taken off” (Executive Director of Information Services).

And,

“They are not practiced very much in the wider business community. Organisations are well-organised and using lots of tools to put their products in the marketplace rather than actually managing knowledge” (Senior Academic).

A second view was that the concepts have had an impact in highlighting the role people play in creating value for organisations: 
“Managing knowledge means managing people” (Head of UK based Research School).

They had also improved the general perception of information professionals in the wider business community by:
"Unlinking with the traditional ideas of the information professional”(University Librarian).

The interviewees saw the concepts had an impact on the people management rather than information management capabilities of organisations. They highlighted individual employee inputs and competencies. In practice, they had little impact, according to our interviewees, being still based largely in theory.

Theme 3. The acquisition and use of information and the embedding of good practice.

The information auditing literature (Orna, 1999, Henczel, 2001) has highlighted the missed opportunities which organisations face when they do not embed lessons learned from information management but expend their energies in acquiring and using masses of information which may or may not fulfil business objectives. Organisational learning is defined as:

"The transference of learning from individuals and groups through the learning that becomes embedded - or institutionalised - in the form of systems, structures, strategies and procedures.” (Crossan, Lane and White, 1999, p. 524).

The leveraging of information assets to create business value depends on organisations and their members successfully acquiring, using and embedding good information management practice. The vast majority of organisations carry out acquisition and use of information successfully. Yet, when lessons are to be learned these are often not recognised and as a result when similar problems reoccur new solutions have to be found. There is little reuse or 
evaluation of existing information assets. Such use of information assets becomes mechanistic rather than creative so that innovation is limited.

The interviewees did recognise a disparity between an organisation's effectiveness in acquiring, using and embedding information assets. They saw a role for information professionals in enabling organisations to move towards the concept of a learning organisation. Indeed all employees and the information systems they used had a role to play in developing a learning organisation. Embedding good information management practice was, however, a difficult task:

"Have to learn how to be learning organisations. Knowledge management systems can help with that. Need to involve all employees but encouraging sharing and exchange of information is an uphill battle. Have to set up processes, which are built into work rather than trying to change the culture. If it is not built into the system then people will ignore it” (Senior Academic).

And,

"There is a role for everybody in handling information but some have an advanced role” (Research Director).

The Director of Information Services saw the lack of embedding of good practice as an education issue. Organisations and their members simply did not understand the issues which information management engendered. It was the role of information professionals to address this.

"There is a prime need to educate people. It is difficult to embed good information management practices as there is a lack of understanding of information issues. Need to be realistic and practical and information professionals need to meet the challenges”. 
The University Librarian who argued that organisations would embed good information management practice only when they could see that real improvements were being made offered a differing viewpoint. Information professionals needed to create more opportunities for good practice.

"Need to see improvement rather than embed it. Offer more opportunities for lessons to be learnt or organisations will find other people to do it”.

Theme 4. The relevance of these questions to other industry sectors. Are they more relevant issues for some sectors?

The relevance of issues such as the value of information, the impact of knowledge management and intellectual capital and the embedding of good practice to areas other than the information-intensive organisations we targeted in our case study work (Oppenheim, Stenson and Wilson, 2002) was of interest in evaluating whether our research was capable of being applied to other industry sectors. The six internationally-active information professionals and academics were well positioned to provide comments on this.

Two of the interviewees, Senior Academic and Director of Information Services saw these issues as of greatest importance in the health sector. This was because:

"The health sector is more important. They have an impact on decision-making processes and information gathering” (Senior Academic).

And,

\footnotetext{
“The health sector - technology has given information professionals opportunity to be pro-active rather than reactive (Director of Information Services).
} 
The Head of UK based Research School argued that there were sectors where these issues were not of importance, for example, in running small bed and breakfasts, but added:

"I would be very surprised to find a sector which did not need to address the problem” (Head of UK based Research School).

The Executive Director of Information Services saw the issues as of more relevance to academia and education especially as distance learning provided students with increasing choice in their learning experience.

"Education and education on-site versus distance education”.

The Research Director saw the issues as of more relevance to fast-paced and time-sensitive industries rather than slow-moving industries:

"More relevant to time-sensitive industries like financial investing rather than slow-moving industries like manufacturing”.

Finally, the University Librarian saw them as of more relevance to the profit sector and the not for profit sector where there was a need to be accountable:

"More relevant to the profit sector or sectors in the not-for-profit sector where there is a need to be accountable eg. Government agencies”.

Overall, the six interviewees saw the issues of value of information, the impact of knowledge management and intellectual capital and the embedding of good practice as relevant to a wide range of sectors but these were predominantly information-intensive such as the health sector, education and financial services. This may indicate that there is little scope for applying these issues to more traditional industry sectors. 
Theme 5. Identification of attributes of information as an asset.

Identifying attributes of information as an asset was a primary objective of the research project "The attributes of information as an asset, its measurement and role in enhancing organisational effectiveness" for which these interviews were conducted. Earlier interviews to identify attributes of information assets (Oppenheim, Stenson and Wilson, 2002) had identified two major types of attributes, those integral to the information asset itself such as utility and those, which arose from use of information assets such as improved effectiveness or productivity. Of primary interest for these interviews, however, was the ability of individuals to recognise that information assets did have unique attributes, which could either enhance or hinder their exploitation. We asked the six internationally-active information professionals to identify attributes of a given set of information assets so as to test whether these highly experienced individuals found it easy or difficult to identify attributes. Overall, there was little difficulty in discerning attributes and a wide range were identified:

\section{Head of UK based Research School}

Assets

Customer information

Competitor information

Product information

Business processes

Management information

People information

Supplier information

Legal and regulatory

Organisational information

"Culture”

\section{Senior Academic}

Assets

Customer information

Competitor information
Attributes

Accuracy Timeliness

Thinking

Expertise

Rely on people

Accuracy

Accuracy

Extremely timely

Background information

Limited need

Attributes

Degree of understanding

Timeliness Accuracy Relevance 
Product information

Business processes

Management information

People information

Supplier information

Legal and regulatory

Organisational information

"Culture"
Detail Timeliness Accuracy Accessibility Timeliness Accuracy Accessibility Availability

Summarised form Sensitivity to

confidential information Accuracy

Accessibility

Granularity

Accuracy Know what is available

Timeliness Accessibility

Stumbling distance

Complicated Learn culture Participate

\section{Executive Director of Information Services}

Assets

Customer information

Competitor information

Product information

Business processes

Management information

People information

Supplier information

Legal and regulatory

Organisational information

"Culture"

\section{Research Director}

Assets

Customer information

Competitor information

Product information

Business processes

Management information

People information
Attributes

Insightful Depth

Benchmarking

Price

Depth Differentiation

Focus

Honesty

Completeness

Format Accurate Up to date

Essential Completeness
Attributes

Importance

Situational

Timeliness Accuracy

Situational

Accuracy

Political dimensions 
Supplier information

Legal and regulatory

Organisational information

"Culture”

\section{University Librarian}

Assets

Customer information

Competitor information

Product information

Business processes

Management information

People information

Supplier information

Legal and regulatory

Organisational information

"Culture”

Director of Information Services
Timeliness Accuracy

Situational

Facets Political dimensions

Attributes

Communication Day to day operations

Resource needs

Benchmarking

Understanding

Communication

Accuracy

Expectations Performance

Day to day operations

Necessary

Understanding

Accuracy and Timeliness were the attributes most often identified. However, a whole range of attributes such as Communication, Understanding and even Honesty also emerged as central concerns of the interviewees. This indicates that not only can inherent attributes of information assets be readily identified but that less tangible and esoteric attributes are also of interest and should be explored more fully.

Theme 6. Information assets and organisational effectiveness. 
Organisational effectiveness is defined as:

\section{An organisation is effective to the extent that it achieves what it sets out to achieve and the route to this involves doing the right things.}

The role of information assets in enhancing organisational effectiveness is a difficult area to define. While information assets underpin many organisational activities they are often not identifiable as separate value creating entities. While they contribute to organisational effectiveness their impact is often hidden until they are either removed or lost. Five of the interviewees said that they saw a role for information assets in enhancing organisational effectiveness. One (Research Director) argued that information assets and organisational effectiveness could not be separated from the political dimensions of organisations. In other words, no amount of good information management would counter a political environment where information did not signify:

“No what matters is politics” (Research Director).

Among those who did see a role for information assets in enhancing organisational effectiveness difficulties were also identified:

"Information management can make organisations more effective but it is very difficult to isolate information as the key factor” (Head of UK based Research School).

And,

"Information can improve effectiveness but have to apply yourself to using information and build use into systems” (Senior Academic).

Theme 7. Impact of identification and measurement of information assets on the perceptions of senior managers. 
This question was based on the assertion by Eaton and Bawden (1991, p.163) that the value of information was dependent on "context and use” and that attempts to measure it simply limited its dynamic capabilities. Eaton and Bawden (1991, p.156) pointed out "if information is a resource, it is different in kind from most others". They argued that identifying information as a resource had become shorthand for "information is important." The value of information was not quantifiable (Eaton and Bawden, 1991, p.163). In other words, concentration on quantifying information detracted from the dynamic role which information played in organisations. Attempts to measure value limited the dynamic nature of information and ultimately destroyed innovation in organisations.

However, in our view, the subjectivity and the situational nature of information value needs to be balanced with the need to manage and exploit information assets for enhanced organisational effectiveness. Our research sought to argue that while the value of information was subjective, attempts to measure value did have a positive impact on the perceptions of senior managers. Such attempts helped to make concrete abstract concepts such as information, thereby improving understanding and ultimately creating greater opportunities for the exploitation of information assets.

The interviewees were divided on this issue. The Head of the UK based Research School argued:

"Recognition of information is already apparent. There is evidence in very large firms. Measurement is not in conflict with creative applications”.

The Senior Academic also argued:

"Need to demonstrate value if organisations are going to take advantage. It is a real asset that does not blow away in the wind. The more you demonstrate the value the more value will be put on it”. 
Conversely, the Director of Information Services argued that:

"Depends on learning style of the organisation. Can convince some people by measuring others see it as time wasting. Measurement is not neutral it affects performance and this can affect dynamic role of information”.

And,

$$
\begin{aligned}
& \text { "Depends on the culture of the organisation. Can have unobtrusive } \\
& \text { measurement. Use v understanding are two very different parts of } \\
& \text { information management" (University Librarian). }
\end{aligned}
$$

The use of information was emphasised by the University Librarian as an area where our research had potential to uncover examples of how information assets helped senior managers to create value for their organisations. We had concentrated on the identification and measurement of attributes of information assets rather than their use. In subsequent case studies for the research project we included use of information assets in non-routine decision making as a critical issue. The research project benefited greatly from having practical examples of information assets in use to demonstrate the importance of information assets.

\section{Conclusion}

The six internationally-active information professionals did prove to have strong and considered opinions which arose out of many years experience in the information and libraries field. On some of the themes, they were divided, but some consensus emerged from the others. They agreed that a focus on valuing information assets is not appropriate despite its apparent attractiveness; instead, the focus of research in this field should be on the use of information assets for securing long term future benefits for the organisation. They felt that people management was as important as information management, and that an important role for information professionals is to lead the organisation in a 
change towards becoming a learning organisation. Information assets were, perhaps unsurprisingly, considered particularly important in informationintensive, fast changing organisations. Finally, they concluded that accuracy and timeliness were the most important attributes of good information assets.

In addition, our interviewees clarified many of the issues the research project team were investigating. Most importantly, they encouraged us to take an open rather than limited view of information assets and their impact on organisational effectiveness. They also helped in the design of later case studies for the research project, highlighting the situational nature of information use and the importance of obtaining examples of information use in organisations. Although largely informal, the interviews were invaluable in providing assurance that the issues we were addressing in this research project were of relevance to information professionals and academics who were expert in their field. This encouraged us to continue with our approach which did prove successful in uncovering a range of issues in the information as an asset domain. 


\section{Bibliography}

Abell A. (1994) An information policy for Business Link Hertfordshire, Hertfordshire, University of Hertfordshire Press.

Best, D. (1996) “Business process and information management” in Best D. (ed) The Fourth Resource: information and its management, Aldershot, Aslib/Gower.

Brimson, J.A. (1991) Activity accounting - an activity-based costing approach, New York, Wiley.

Crossan, M., Lane, H.W. and White, R.E. (1999) “An organisational learning framework: from intuition to institution”, Academy of Management Review, 24 (3), p. 522-537.

Drucker, P.F. (1969) The age of discontinuity: guidelines to our changing society, London, Heinemann.

Eaton J.J. and Bawden, D. (1991) “What kind of resource is information?”, International Journal of Information Management, 11(2), p156-165.

Edvinsson, L. and Malone, M. (1997) Intellectual capital: realising your company's true value by finding its hidden brainpower, New York, HarperBusiness.

Glaser, B. and Strauss, A. (1967) The discovery of grounded theory: strategies for qualitative research, London, Weidenfeld and Nicolson.

Henczel, S. (2001) The information audit: a practical guide, München, K-GSaur. 
Oppenheim, C., Stenson, J. and Wilson, R.M.S. (2001) “The attributes of information as an asset, its measurement and role in enhancing organisational effectiveness", Proceedings of the $4^{\text {th }}$ Northumbria Conference on Performance Measurement in Library and Information Services, Washington, Association of Research Libraries, p. 197-202.

Oppenheim, C., Stenson, J. and Wilson, R.M.S. (2002) "Studies on information as an asset: Definition”, “Studies on information as an asset: Repertory Grid”, Journal of Information Science (Forthcoming).

Orna, E. (1999) Practical information policies, (2 ${ }^{\text {nd }}$ ed.) Gower, Aldershot.

Peters, T. (1992) Liberation management: necessary disorganisation for the nanosecond nineties, London, Macmillan.

Polyani, M. (1958) Personal knowledge: towards a post-critical philosophy, Chicago, University of Chicago Press.

Skyrme, D.J. (1998) Measuring the value of knowledge. London, Business Intelligence Ltd.

Wilson, T.D. (2002) “The nonsense of knowledge management”, Information Research, 8 (1). Accessed 5/12/02 Available at:

http://informationr.net/ir/8-1/paper144.html

Yates-Mercer, P. and Bawden, D. (2002) "Managing the paradox: the valuation of knowledge and knowledge management”, Journal of Information Science, 28 (1), 19-29. 


\title{
APPENDIX I
}

Information Experts Interview Schedule

\section{The attributes of information as an asset, its measurement and role in enhancing organisational effectiveness}

\author{
Interviews with Information Experts : Pittsburgh, Pennsylvania, USA, 12th-17 \\ August 2001.
}

\section{Questions}

1. The value of information is increasingly recognised but its measurement is still far from satisfactory. Do you think real progress has been made in the measurement of the value of information or is it an impossible task? Is it even necessary to obtain a value for information assets in an organisation?

2. The concepts of knowledge management and intellectual capital are now widely known and used in the business environment. Do you think they have had a real impact in improving the management of information and highlighting the role of information professionals?

3. Many organisations are good at acquiring and using information. Where they still seem to struggle however is in embedding lessons learnt from information acquisition and use especially in business systems and business processes. Do you think that organisations might benefit from distributing responsibility for embedding good practice in information management to all employees? How could it be achieved? What might such a move mean for the information profession?

4. Are there sectors where these questions are more relevant and important and others where the questions posed above are not of importance? 
5. Of the following information assets listed below, please describe their most significant attribute for you when used in your day to day work.

(The word "asset” is used to signify something of future economic benefit and is not used simply in its conventional accounting sense).

Information Assets
accuracy)
Customer information
Competitor information
Product information
Business processes
Management information
People management
Supplier information
Legal and regulatory
Organisational information

Attributes (for example,

6. Do you think better information management can improve an organisation's effectiveness? Will organisations that do not apply themselves to identifying and harnessing their information be less successful than those who do? Can this be measured?

7. Finally, do you think that identifying and measuring information and its value will have a positive impact on the perception of information by senior managers? Or is a culture of assessment detracting attention from the dynamic role information plays in organisations and even perhaps curtailing its creative applications?

Are there any other points you would like to raise? 